\title{
Go Figure: Calculus Students' Use of Figures and Graphs in Technical Report Writing
}

Thomas J. Pfaff

Ithaca College, tpfaff@ithaca.edu

Michael Rogers

IthacaCollege,mrogers@ithaca.edu

Ali Erkan

Ithaca College, aerkan@ithaca.edu

Jason G. Hamilton

Ithaca College, jhamilton@ithaca.edu

Follow this and additional works at: https://digitalcommons.usf.edu/numeracy

Part of the Mathematics Commons, and the Science and Mathematics Education Commons

\section{Recommended Citation}

Pfaff, Thomas J., Michael Rogers, Ali Erkan, and Jason G. Hamilton. "Go Figure: Calculus Students' Use of Figures and Graphs in Technical Report Writing." Numeracy 4, Iss. 1 (2011): Article 6. DOI:

http://dx.doi.org/10.5038/1936-4660.4.1.6 


\title{
Go Figure: Calculus Students' Use of Figures and Graphs in Technical Report Writing
}

\begin{abstract}
Understanding how to read and use graphs to communicate scientific and mathematical information is critical for STEM majors, as well as an important part of quantitative literacy. Our study suggests that first-semester calculus students do not know how to use graphs in a technical report without explicit instruction. Although not a surprising result, it leaves us wondering about when such skills are developed, and if calculus I is a place to start. Our work is now exploring the potential benefit on students' use of graphs by having them formally evaluate other students' reports.
\end{abstract}

\section{Keywords}

Calculus, Technical Writing, Quantitiative Literacy

\section{Creative Commons License}

\section{(c) (i) (5)}

This work is licensed under a Creative Commons Attribution-Noncommercial 4.0 License

\section{Cover Page Footnote}

Thomas J. Pfaff is an Associate Professor of Mathematics at Ithaca College. His main teaching interest is incorporating sustainability into the courses he teaches. He maintains a page of sustainability curriculum materials at http://www.ithaca.edu/tpfaff/sustainability.htm

Michael "Bodhi" Rogers is an Associate Professor of Physics at Ithaca College. He has a Ph.D. in physics and a Masters in archaeology, both from Oregon State University. Rogers' primary scholarly interests are Astronomy and Physics Education Research and Archaeological Geophysics.

Ali Erkan is an Associate Professor of Computer Science at Ithaca College. His research interests include the exploration of wiki-based systems as a tool to quantify the extent of pedagogically significant factors which have historically been studied in qualitative terms.

Jason Hamilton is an Associate Professor and founding faculty member of the newly formed Department of Environmental Studies and Sciences at Ithaca College. A global change biologist, Hamilton has worked to develop theories and practices of sustainability and sustainability education. 


\section{Introduction}

Being able to read and work with figures and graphs is on numerous lists of skills for quantitative literacy (QL) (e.g., Sons 1996, part 2; Steen 2001, p. 15-17; Steen 2004, p. 91-94). In their work with QL across the curriculum, Steele and KiliçBahi (2010) recently assessed student's graphical skills as part of a program implementing QL across the curriculum, stating that

Students should be able to understand multiple ways of presenting data in graphs and tables. They should be able to draw conclusions from data presented in newspaper, TV, or Internet articles, and even be able to point out flaws or omissions in the presentation (Steele and Kiliç-Bahi 2010, p. 4).

In our work on creating and implementing a multidisciplinary sustainability module (Hamilton et. al. 2010), we encountered work by students that forced us to ask how well students in fact contextualize graphs. That is, even if students are capable of reading a graph, do they comprehend and make the connection between graphs and figures in articles and the text within? In other words, do students recognize and connect the graphs and figures with the story they support.

Although quantitative literacy isn't a main goal of our module, the fact that we are tackling real-world problems has added quantitative literacy to our calculus course. As part of the module, students curve fit global climate data and write a technical report to discuss rates of temperature increase and to make projections based on simple models. Curriculum enhancements in Calculus I courses have the potential to impact large numbers of students, and proper use of figures is a critical component of clear technical writing and quantitative literacy. These types of enhancements are important as it has been noted that

...only a small part of the education needed to attain control over numbers can be found in the typical mathematics curriculum. That is because skills in complex counting and data analysis, like many other aspects of numeracy described in the case statement, rarely find a place in the standard calculus-oriented mathematics progression (Orrill 2001, p. xviii).

In this note, we report what we saw when students were asked to include a figure (graph) in a technical report.

\section{Methods}

Our observations are based on the technical reports produced by first-semester calculus students when they were asked to communicate their findings to their peers in other courses which were collectively engaged in a multidisciplinary sustainability education module. The module's main goals are for students (i) to develop an understanding of the characteristics of $21^{\text {st }}$ century problems, (ii) to experience the necessity of cooperation between different disciplines to address these complex problems, (iii) to work with real-world problems for increased 
engagement in learning, and (iv) to learn calculus better. It is important to stress that we did not set out to assess or evaluate quantitative literacy skills.

The calculus part of the "What is the current and future impact of global climate change on polar bears?" module requires students to use MS Excel to curve fit average global temperature data from NASA (Hansen 2010); as discussed in Pfaff (in press), this is an effective way to incorporate interesting issues into calculus and to better engage students with real-world examples. In order to communicate their results on rates of temperature change and their predictions of future temperature, students were required to write a technical report as part of the module. To define the results and discussion sections of the expected report, we gave the students the following instructions (which were modified from instructions currently used by the Ithaca College physics department in their upper-level laboratory courses):

Results: You must present the results of your work in this section. Common presentation methods are tables and figures where figures can contain graphs, pictures, photographs, or other images. Most people who read a technical report look at the figures in the report first; as such, your figures should completely describe your results. Be wary of too few or too many figures. Figures are perhaps the most important part of the whole technical report, and many people create the figures first and write the paper around the figures.

Discussion: This section is where you discuss the ramifications of your results and your confidence in those results. You should include a discussion of uncertainties. This is the section where all of the elements should be tied together with a compelling narrative. This is where you explain IN ENGLISH WORDS what your results show and what you have determined. In other words, why should anyone care about your work?

As can be seen, there is a clearly stated expectation that the results section should include a figure, and we did not think we needed to provide any details on how to incorporate a figure into the report. Our results are from 15 reports written by 43 students (all but two reports were by a group of three students) who were taking Calculus I in the fall of 2009.

\section{Results}

Of the 15 reports, 14 contained an appropriate scatter plot including a curve fit. Of those 14, four also included the tangent line. An ideal example of a scatter plot with a curve fit and a tangent line is shown in Figure 1. These results aren't surprising as students were told to include a graph (the group that didn't have a graph similar to the example provided did include a graph) and were taught how to make a scatter plot with a fitted curve in Excel. Ideally students would include the tangent line, but they weren't taught how to do this and it takes a little more work to add it to the graph in Excel. 


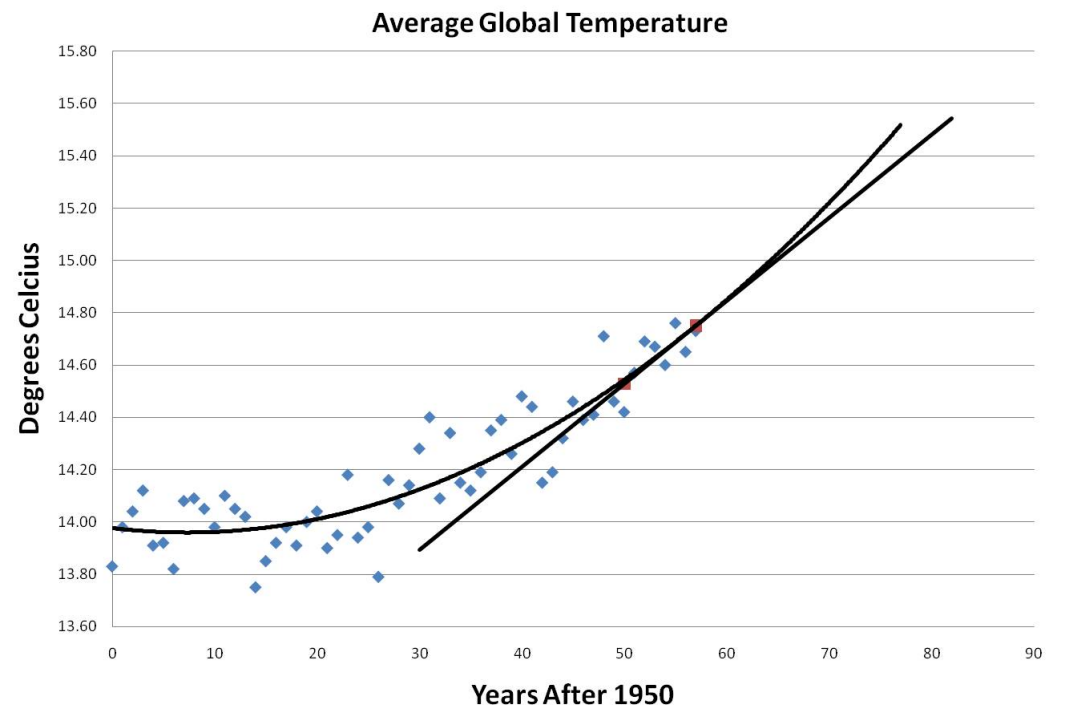

Figure 1. A scatter plot of average global temperature in degrees Celsius in years after 1950, along with a quadratic fit and tangent line to the curve in 2007.

What surprised us was that only three of the 14 figures had a caption, and only three labeled their graph as a figure (e.g., "Figure 1"). Two groups that labeled the graph had a caption; one group labeled the graph without a caption; and one had a caption but didn't label it. We gave credit to six of the reports referencing the graph, but only one group actually referenced the graph as "Figure 1." Typically, students referenced the graph by saying "the graph below" or "the graph in the results section."

\section{Discussion}

It is clear that students were careful in following our instructions; all reports had a figure and all but one was appropriate. But they also revealed that their sense of written communication is not fully formed since the need to associate a visual with the supporting description was often missing (to the point that we now know we have to provide explicit instructions to address this problem).

Certainly we have a small sample and we could dismiss the issue as students not giving sufficient thought as to how they incorporate figures, graphs, tables into the reports they produce. Still, more than half of the reports made no connection at all between the graphs they included and the text, and those that did were typically cursory. However, this observation might be telling us something more serious about how students read reports/articles as well. These are Calculus I students and their math and science texts do label and reference graphs properly. 
If a student does not connect the visual quantitative information to the explanation or data that go with it, the student is likely viewing these visuals as separate objects. This makes us wonder about the extent to which students actually even look at visuals; consequently, we wonder whether students fully understand what they read. Again, our goal in these reports was not to assess their use of graphs and figures. Rather, we were surprised at the students' poor use of their graphs, in general, and as supporting evidence for their work.

\section{Concluding Remarks}

Good figures and graphs relay an abundance of quantitative information that supports the thesis of the text. If students are ignoring this information, then they are ignoring the data that attempt to back up the thesis of the text. This thought leaves us with the questions of (i) where do students learn to use figures appropriately, and (ii) where do they learn how to analyze figures as part of articles they read? A comparison group of junior- and senior-level physics students who were part of our study were given a similar assignment and had no problem properly incorporating graphs. It seems that they have learned this skill somewhere, but it leaves us wondering when and how the physics students are learning this skill. It may be the case that science students, or at least our physics majors, are learning how to use figures and graphs from taking multiple laboratory courses. Unfortunately, we don't have a comparable upper-level math group for a comparison, or any upper-level non-science group, but we would like to incorporate such a group into our on-going work. We are also currently looking at the impact on student use of graphs by having students evaluate other students' technical reports, using an instructor-generated rubric. We feel strongly that reading graphs and using graphs in writing need to be explicitly taught repeatedly, in multiple courses, as part of quantitative literacy that connects data, graphs, figures, and other visual representations to the associated text.

\section{Acknowledgements}

This work was supported by the NSF grant DUE-0837721, Multidisciplinary Sustainability Modules: Integrating STEM Courses.

\section{References}

Hamilton J.G., M. Rogers, T.J. Pfaff, and A. Erkan. 2010. Multidisciplinary collaborations in the traditional classroom: Wrestling with global climate change to improve science education. Transformations: The Journal of Inclusive Scholarship and Pedagogy, 21(1): 89-98. 
Hansen, J. GLOBAL temperature anomalies in 0.01 degrees Celsius. http://data.giss.nasa.gov/gistemp/tabledata/GLB.Ts.txt (accessed Nov. 4, 2010).

Orrill, R. 2001. Mathematics, numeracy, and democracy. In Mathematics and democracy: The case for quantitative literacy, ed. L. A. Steen, xiii-xx. Washington DC: National Council on Education and the Disciplines, The Woodrow Wilson National Fellowship Foundation.

Pfaff, T. Educating students about sustainability while enhancing calculus. PRIMUS: Problems, Resources, and Issues in Mathematics Undergraduate Studies (in press).

Sons, L. 1996. Quantitative reasoning for college graduates: A supplement to the Standards. Washington DC.: Mathematical Association of America. http://www.maa.org/past/ql/ql_toc.html (accessed Nov. 4, 2010).

Steele, B., and S. Kiliç-Bahi. 2010. Quantitative literacy: Does it work? Evaluation of student outcomes at Colby-Sawyer College. Numeracy 3(2): Article 3. http://dx.doi.org/10.5038/1936-4660.3.2.3 (accessed Nov. 4, 2010).

Steen, Lynn Arthur, ed. 2001. Mathematics and democracy: The case for quantitative literacy. Washington, DC: Woodrow Wilson National Fellowship Foundation. http://www.maa.org/q1/mathanddemocracy.html (accessed Nov. 4, 2010).

- 2004. Achieving quantitative literacy: An urgent challenge for higher education, MAA Notes 62. Washington DC: Mathematical Association of America. 